\title{
RETOS Y ALTERNATIVAS DE LA GESTIÓN LOCAL DEL AGUA EN LA PERIFERIA URBANA de San Cristóbal de Las Casas, Chiapas
}

\author{
Challenges and Alternatives Concerning Local Management of Water in the Suburbs \\ of San Cristobal de Las Casas, Chiapas
}

Antonieta Zárate-Toledo

Resumen: En este artículo se analizan las relaciones sociales que se establecen en torno al agua y los bosques, así como las tensiones y conflictos que se asocian a este proceso en contextos periurbanos. Partimos del estudio de las estrategias y prácticas de acceso, abasto, manejo y control del agua adoptadas por actores urbanos y rurales que cohabitan las áreas periurbanas de San Cristóbal de Las Casas, Chiapas. Los resultados se basan en trabajo de campo, entrevistas a profundidad y observación participanterealizados en la comunidad de Los Alcanfores. Enel caso que se presenta, las estrategias de gestión local se han visto presionadas por cambios sociales derivados del crecimiento poblacional.

Palabras clave: abastecimiento de agua, gestión de los recursos hídricos, actores locales, participación comunitaria, comités de agua, zonas urbanas, crecimiento demográfico.

Abstract: In this article, we analyze the social relationships that are established around water and forest resources, as well as the tensions and conflicts that are associated with this process in urban periphery contexts. We start from the study of the strategies and practices of access, supply, management and control of the water adopted by urban and rural actors that cohabit the periphery-urban areas of San Cristobal de Las Casas, Chiapas. The results of this study are based on field work, in-depth interviews and participant observation carried out in the Los Alcanfores community. In the case presented, local management strategies have been pressured by social changes derived from population growth.

Keywords: water supply, water resources management, local stakeholders, community participation, water committees, urban areas, population increase. 
A lo largo del siglo XX, el Estado mexicano fungió como figura central en la gestión de los recursos hídricos del país. Durante este periodo la política pública hídrica se enfocó en el desarrollo de la gran hidráulica, dejando de lado los sistemas locales de abastecimiento de agua — riego y consumo humano-, en los cuales los usuarios tienen un papel central. No obstante, en el marco de dicho proceso las experiencias de gestión local del agua subsistieron y se diversificaron, evidenciando con ello los límites del modelo de gestión centralizada del agua, en la medida en que las instituciones del Estado no han sido capaces de regular de forma sistemática los usos del agua a lo largo del territorio nacional, particularmente en las zonas rurales (Aboites, 2009).

En la actualidad, en la gestión del agua en México se sigue priorizando garantizar volúmenes crecientes de agua para el abastecimiento de la industria, la agricultura de exportación, los servicios y las grandes ciudades, mientras que en amplias zonas rurales, pero también ciudades medias, prevalecen rezagos en infraestructura para el abastecimiento humano y para la irrigación. En estas áreas prosperaron las formas locales de gestión, basadas en arreglos y normas locales que permiten regular el acceso a fuentes de agua de menor escala.

El estado de Chiapas cuenta con una disponibilidad de agua superior a la media nacional gracias a los volúmenes de precipitación que en promedio ascienden a 1846 milímetros anuales (CONAGUA, 2014). La región Altos de Chiapas, al estar asentada en un macizo montañoso con estribaciones que alcanzan hasta los dos mil metros sobre el nivel del mar, recibe importantes precipitaciones estacionales que la convierten en un área de importancia para el desarrollo de actividades económicas. No obstante los altos niveles de disponibilidad de agua, en Chiapas se carece de infraestructura para el riego y el consumo humano, y la cobertura de servicio de agua entubada y alcantarillado en el estado es del $73.5 \%$, porcentaje inferior a la media nacional (CONAGUA, 2011). Ello contrasta con la existencia de un complejo sistema generador de hidroelectricidad integrado por cuatro presas emplazadas en el río Grijalva, con una capacidad de generación que equivale al 45\% del agua a nivel nacional (Kauffer, 2009: 402).

En Los Altos de Chiapas, ante la ausencia del Estado para construir obras de abastecimiento para la población, prevalecieron los sistemas antiguos de abastecimiento tanto en el medio rural, como en el urbano. En consecuencia, en la región se observa un mayor control local de los recursos hídricos, frente a la ausencia u omisión de las instituciones del Estado mexicano, de manera que los grupos locales lograron desarrollar un esquema local de control del agua alterno y muchas veces opuesto a las instituciones oficiales.

San Cristóbal de Las Casas es el principal centro urbano de la región Altos de Chiapas. Durante la década de 1990 experimentó un acelerado crecimiento urbano que ha provocado un cambio en el uso del suelo en las áreas boscosas ubicadas en las laderas de las montañas que circundan la mancha urbana. Este hecho se ha traducido en una considerable presión sobre los recursos naturales en dichas áreas y ha generado disputas por la tierra y el agua entre los actores rurales - habitantes de las comunidades rurales - y urbanos -nuevos pobladores que acuden a estas áreas en busca de terrenos para vivienda- (Zárate, 2008). También ha provocado una serie de problemáticas en torno al acceso a los servicios urbanos, particularmente al agua para uso doméstico.

En este trabajo buscamos analizar las relaciones sociales que los habitantes de las zonas periurbanas de San Cristóbal de Las Casas establecen para el acceso, uso y distribución del agua, así como las tensiones y conflictos que se asocian con este proceso. Consideramos el conjunto de relaciones sociales que se establecen en torno al agua como una forma de institucionalidad local, la cual incluye normas y reglas que regulan el uso y acceso a los recursos. En un contexto de crecimiento poblacional que ejerce una presión creciente sobre los recursos hídricos, y en el marco de los cambios en las políticas públicas que regulan el uso y acceso a estos recursos, las comunidades locales afrontan el reto de preservar sus prácticas tradicionales en torno al agua y así mantener el control y la autonomía sobre las fuentes 
de las cuales se abastecen, al replantear sus estrategias de apropiación y gestión del recurso.

En este texto se analizan las formas locales de gestión del agua con la finalidad de visibilizar la importancia que estos procesos tienen para la gestión social del agua en el país. La hipótesis que guía el análisis es que la gestión local del agua como bien común, forma que ha sido históricamente adoptada en Los Alcanfores, genera conflictos al adaptarse a las nuevas condiciones de crecimiento poblacional y a la concertación de acuerdos respecto a la reserva natural en la que se localiza el recurso, así como a las transformaciones de las políticas públicas en torno al agua.

Dividimos la exposición en cuatro partes: en la primera se discuten los conceptos de gestión local del agua que guían el análisis de este caso de estudio. Posteriormente se analizan los procesos históricoterritoriales que atraviesan la problemática de la gestión del agua en la comunidad. En tercer lugar se argumenta en torno a las formas de apropiación y gestión del agua en Los Alcanfores, y se continúa con el tratamiento de los conflictos y tensiones en torno a la gestión del recurso y las estrategias adoptadas por la comunidad de Los Alcanfores para hacer frente a ellos, para finalmente presentar las conclusiones.

Para esta investigación, de carácter cualitativo, se realizaron entrevistas a profundidad a actores clave de Los Alcanfores principalmente, así como a autoridades municipales y funcionarios de los gobiernos estatal y federal, junto con otras estrategias metodológicas como trabajo de campo, observación participante y trabajo de archivo en los registros agrarios regionales.

\section{Gestión local del agua e instituciones: de la apropiación a la regulación}

La gestión local del agua se refiere al proceso completo de toma de decisiones en torno al diseño y operación de mecanismos de manejo de los recursos hídricos a fin de aprovecharlos o preservarlos, proceso con el cual se pretende garantizar el acceso colectivo a los mismos. Para sistematizar el concepto de gestión local del agua, autores como Boelens y Hoogendam (2001) proponen identificar los siguientes elementos: 1) el marco tecnológico de la infraestructura del agua - que incluye la construcción, operación y mantenimiento del sistema-;2) las normas bajo las cuales se define el acceso y uso del recurso hídrico y las obligaciones y sanciones; 3) las estrategias organizativas, que incluyen las estructuras y funciones organizativas para la gestión, las formas y tipo de autoridades para la toma de decisiones, el manejo de conflictos, la movilización de recursos y las formas de vigilancia, monitoreo y control social; 4) la operación de las normas de gestión de agua en la práctica, es decir, la planificación de turnos y distribución del agua, en las que prima el orden planificación-y luego su ejecución —distribución-; 5) la gestión interinstitucional, que se refiere a cómo los gestores locales se relacionan con la legislación oficial y los legisladores, cómo negocian y conciertan con sistemas de terceros, y también su posicionamiento, en algunos casos, en el mercado de derechos de agua; $y$, finalmente, 6) las estrategias de conservación del agua y las áreas de captación como los bosques.

En Los Altos de Chiapas, el manejo y control del agua es un aspecto central en la organización de las comunidades. La regulación de las formas de apropiación y uso del agua, así como la definición de las reglas de acceso al recurso, constituyen aspectos esenciales para el control del territorio de las comunidades rurales que habitan en la región. De esta manera, agua y territorio son elementos imposibles de separar, por lo que el acceso al agua forma parte de los derechos territoriales colectivos (Burguete, 2000).

Para comprender las estrategias de gestión del agua es preciso retomar el concepto de institución. Desde la perspectiva de Appendini y Nuijtten, las instituciones son: "órdenes negociados que son construidos, mantenidos y transformados por la interacción social" (2002). Esta noción no solamente incluye el aspecto normativo, sino también se vincula con las "relaciones de poder y dominación más amplias y pueden reproducir las obligaciones ideológicas y políticas en las cuales están atadas" (Appendini y Nuijtten, 2002: 75). Esta definición de institución involucra una carga cultural en la medida que sugiere que las instituciones 
forman parte de un proceso de creación y promulgación culturales.

De acuerdo con lo anterior, la institucionalidad que se construye en torno al agua en el caso estudiado se estructura a partir de una serie de prácticas y estrategias organizativas que permiten a la población local regular el acceso al recurso. Estas prácticas se desarrollan en un marco de transformaciones sociales, donde la intervención de nuevos actores con visiones encontradas pone en juego considerar el agua como un bien o recurso económico que busca su mayor utilidad en el mercado de bienes transables, o como un bien social, cultural y un derecho humano, integrado en una visión holística del medioambiente. Desde esta perspectiva, el reto para la comunidad estudiada es desarrollar arreglos sociales que le permitan seguir ejerciendo el control en torno a los recursos hídricos y el territorio.

\section{Transformaciones territoriales recientes en Los Alcanfores}

La ciudad de San Cristóbal de Las Casas es el principal asentamiento urbano de la región de Los Altos de Chiapas. Fue fundada por los españoles en 1528 y se ubica en un territorio geográfico de tipo lacustre. El asentamiento urbano se emplazó estratégicamente en la parte más baja y plana de la cuenca, rodeado por ríos y "barrios amigos" (Aubry, 1991), estos últimos habitados por grupos indígenas aliados a los conquistadores y que tenían orígenes náhuatl, zapoteco, mixteco y maya quiché, así como por ladinos y mestizos. Dichos "barrios amigos" cumplían la función de resguardar a la población criolla de las posibles invasiones de los pueblos tsotsiles que se resistían a la colonización. Los ríos y montañas que franqueaban el núcleo urbano colonial sirvieron para controlar el acceso a la ciudad; sin embargo, las condiciones geográficas pusieron a la localidad a merced de inundaciones periódicas. En 1976 se creó un túnel para el drenaje de la cuenca y para mitigar dicha problemática. Como resultado, se drenaron vastas áreas de humedales en la cuenca de Jovel, las cuales quedaron a disposición de la ocupación urbana. A partir de ello se desató una espiral de crecimiento poblacional que se intensificó en la segunda mitad de la década de 1990, cuando a raíz de los conflictos sociales en las zonas cercanas, predominantemente indígenas, la ciudad de San Cristóbal de Las Casas recibió una importante afluencia de población. Los nuevos pobladores se establecieron principalmente en la zona norte del valle, donde crearon asentamientos irregulares.

El asentamiento conocido como Los Alcanfores se localiza en la zona norte poniente de San Cristóbal de Las Casas, en las faldas del volcán Huitepec, y actualmente constituye una de las áreas de mayor presión demográfica identificadas en el Valle de Jovel (Secretaría de Obras Públicas, 2007). ${ }^{1}$ El Huitepec es considerado como uno de los últimos reductos ecológicos de la ciudad ya que en esta zona se localiza una de las pocas áreas de bosque de niebla que todavía perduran en la cuenca de Jovel, razón por la cual se constituye en una de las principales áreas de recarga de los acuíferos.

Las comunidades que originalmente se asentaron en las faldas de este volcán ${ }^{2}$ históricamente han hecho un uso comunitario de los bosques que se localizan en su entorno inmediato, y la apropiación de estas áreas se basa en estrategias y acuerdos intercomunitarios que regulan su uso y acceso. Cabe mencionar que, si bien los pobladores locales hacen un manejo colectivo del territorio en cuestión, legalmente los terrenos en que se localiza la reserva de bosque de niebla de 102 hectáreas en la actualidad tienen el estatuto de terrenos nacionales ${ }^{3}$ (ver mapa l).

Es preciso señalar algunos rasgos históricos de la ocupación social de la cuenca de Jovel. La dinámica sociodemográfica del área del Huitepec se contextualiza en el marco de los procesos históricos de construcción de sistemas socioespaciales del valle de San Cristóbal (Moguel, 1997), y éste, a su vez, en los procesos de construcción de la región de Los Altos de Chiapas, donde el sistema local se caracteriza por la clara delimitación de los espacios habitados por los distintos grupos sociales. Esta diferenciación es de tipo étnico: los "coletos"4 radican en centros urbanos, mientras los indígenas ocupan los espacios rurales; ello, además de 
ser una diferenciación de tipo social, también lo es de carácter espacial en tanto expresa la oposición ciudad/ campo. Al interior del Valle de Jovel el espacio urbano se caracteriza también por una forma de apropiación y uso de la tierra diferenciadamente étnica, donde el centro urbano, que antiguamente se construyó con miras a ser resguardado tanto natural como socialmente, hoy en día continúa siendo ocupado por la élite dominante (Viqueira, 2007). Desde esta perspectiva, el área del Huitepec constituye un espacio periférico claramente diferenciado del centro en cuanto a aspectos sociales se refiere, ya que fue considerado desde sus orígenes como un espacio prácticamente despoblado y hostil —los procesos de ocupación urbana se desarrollaron hacia finales del siglo XX-.

La ocupación del Huitepec ha seguido la lógica antes descrita, y hoy en día en el área prevalece el régimen de pequeña propiedad de la tierra. A esta situación se añade también la problemática de indefinición de límites de las tierras en las faldas del volcán Huitepec, particularmente en las partes altas localizadas en los límites entre San Cristóbal de Las Casas y las tierras comunales de Zinacantán, donde existen aproximadamente 140 hectáreas que quedaron bajo el régimen de terrenos nacionales.

Debido a su estratégica ubicación entre el núcleo urbano y los pueblos indígenas, el Huitepec ha sido escenario de disputas territoriales entre ambos grupos. A lo largo de su historia, los pobladores de esta zona, particularmente de Los Alcanfores, han tenido que adaptarse a los cambios derivados de la presencia de los nuevos pobladores. Uno de estos cambios ha sido el abandono de la actividad agrícola ya que las tierras en las que cultivaban cambiaron de propietarios y se convirtieron en residencias y fraccionamientos de tipo campestre. Aunadas a los cambios territoriales, se han dado también transformaciones en la estructura social de la comunidad, las cuales vinieron a profundizar las antiguas diferencias entre los dueños de las tierras localizadas en las partes más bajas del volcán — quienes han pertenecido históricamente a la élite urbana, hoy representada por los nuevos pobladores- y los habitantes originarios de Los Alcanfores, antiguos peones de las fincas situadas en las partes bajas. Tales transformaciones inciden de manera directa en las estrategias de uso y acceso al agua en la medida en que el sistema municipal no cubre la demanda de este servicio en la zona en cuestión.

De esta forma, la diferenciación en cuanto a las prácticas de apropiación territorial es claramente visible en la comunidad, donde en la parte baja se han desarrollado los procesos más intensos de cambio de uso del suelo, mientras que la parte alta constituye hasta la fecha el núcleo de la población originaria, donde aún prevalecen prácticas agrícolas y manejo comunitario de los bosques.

Finalmente, cabe mencionar que, para fines de planificación, el ayuntamiento de San Cristóbal de Las Casas hasta 1997 consideraba la comunidad de Los Alcanfores como área rural periférica a la ciudad. Hoy en día, si bien la zona baja de la comunidad ha sido incorporada a la carta urbana, ${ }^{5}$ la cobertura del agua potable es prácticamente nula en la medida en que únicamente abarca algunas viviendas, aproximadamente veinte, ubicadas en la parte más baja. Por esta razón, la gestión del agua en la comunidad sigue estando fundada sobre la base de acuerdos intra e intercomunitarios, según los cuales se regula el uso del agua y las áreas de recarga de los manantiales que abastecen a la población.

\section{Estrategias de apropiación del agua en Los Alcanfores: cambios y continuidades en las prácticas tradicionales}

Para fines de este análisis, las prácticas tradicionales de apropiación del agua se definen en sí mismas bajo un esquema de gestión tradicional, la cual se basa en la apropiación y regulación del uso y acceso de una fuente de agua, sea pozo o manantial. Este modo de gestión es característico de los pobladores de las comunidades indígenas de Los Altos de Chiapas, e incluye tanto una dimensión práctica como una simbólica. Los arreglos sociales para acceder a estas fuentes involucran tareas de mantenimiento de la fuente apropiada y los sistemas de distribución, estrategias de conservación de las áreas de recarga, así como una serie de rituales y ceremonias 
que forman parte de la cosmovisión propia de las comunidades indígenas de la región (Burguete, 2000; García, 2005; Murillo, 2005).

En la comunidad de Los Alcanfores se identificaron al menos tres formas de apropiación de los recursos hídricos. La primera de ellas se basa en las prácticas realizadas por la población originaria en la zona alta de la comunidad, que consisten principalmente en el aprovechamiento de escurrimientos que se localizan en el área de bosques; en segundo lugar, las formas de apropiación de los habitantes de la zona baja, que se centra en el sistema de agua entubada administrado por un patronato de agua local; finalmente, la gestión que realizan los avecindados de la parte baja para tener acceso a la red municipal de agua potable y en general, para acceder a otras fuentes alternativas de abastecimiento - compra de pipas de agua y negociación con el dueño de algún predio que cuenta con una fuente de agua para conectarse a ésta, entre otros-.

Antiguamente los pobladores de Los Alcanfores se abastecían de los manantiales que se localizan en las inmediaciones de la comunidad, dos de ellos en la parte norte y, otro más, al sur. Tales manantiales cubrían las necesidades de la población de la zona alta y de algunas familias de la parte baja, mientras que en el área que hoy en día atraviesa la carretera periférica que rodea la ciudad existía una noria que abastecía al resto de la población de la parte baja. A medida que la población fue creciendo, la demanda del recurso se incrementó, lo cual condujo a la adopción de nuevas estrategias organizativas para la apropiación del agua como la construcción de sistemas de captación y distribución, lo que implicó nuevas reglas y mecanismos de regulación del recurso.

En la comunidad existen en la actualidad dos sistemas de distribución del agua, cada uno de los cuales constituye una forma particular de apropiación, uso y manejo del recurso. El primero de ellos abastece a aproximadamente veinte familias de la parte alta de la comunidad y funciona a partir de una serie de acuerdos entre los usuarios que regulan el acceso y el mantenimiento de las fuentes de agua. Por otra parte, en la parte baja existe un sistema independiente de agua que abastece a aproximadamente 180 usuarios, el cual se compone de un sistema de captación, almacenamiento y distribución del recurso que es administrado por un patronato de aguas. ${ }^{6}$ Ambos sistemas se rigen a partir de una serie de acuerdos intracomunitarios que establecen cuáles son las fuentes de abastecimiento, los mecanismos de regulación del uso del recurso y el acceso a él, así como el mantenimiento de cada uno de estos mecanismos.

Es preciso destacar que los mecanismos de gestión del recurso que se realizan en las dos partes de la comunidad se oponen entre sí, ya que ambos se basan en una concepción distinta respecto al recurso. Mientras la parte alta se apega a los mecanismos de gestión tradicional del agua, en la gestión de la parte baja se utilizan cada vez más los mecanismos de manejo institucionales ya que involucra una compleja gama de normas y restricciones en cuanto al uso del agua.

\section{La parte alta: prácticas tradicionales de acceso al agua}

La zona alta de Los Alcanfores está habitada en su mayor parte por población originaria de la comunidad, aunque también se pueden encontrar en ella algunos nuevos residentes o "avecindados". Es la zona que, podría decirse, presenta menor disponibilidad de líquido ya que, por sus características fisiográficas, en ella no existen prácticamente afloramientos de agua, por lo que los vecinos de esta zona adoptan distintas alternativas de apropiación del recurso.

Una buena parte de los pobladores de esta área se abastece de captaciones o galerías filtrantes que construyen en los bosques aledaños a la comunidad, los cuales consisten en zanjas de no más de un metro cuadrado por dos de profundidad en las que el agua se filtra y almacena, y a las que se conectan mangueras para llevar el líquido hasta las viviendas. Actualmente algunas familias han instalado tanques de cemento o tinacos de polipropileno para almacenar el líquido que destinan al consumo doméstico. Frecuentemente se observa que dos o más familias se abastecen de la misma fuente de agua; por lo general, se trata de familias emparentadas que aportan tanto trabajo, como 
dinero, para la construcción y el mantenimiento de las captaciones.

Por otra parte, existen familias que cuentan en sus propiedades con afloramientos y han construido pozos o captaciones como los que hemos referido. Por lo general, la cantidad de agua es suficiente para cubrir sus necesidades, y algunas de las familias comparten la fuente con quienes no tienen agua en sus terrenos. Sin embargo, en la estación seca la cantidad de agua disminuye e incluso algunas de estas fuentes se secan, y con ello las familias con quienes los propietarios de los predios comparten el recurso se ven obligadas a buscar fuentes alternativas para satisfacer sus necesidades. Ello constituye un principio generalmente aceptado, dado que se asume que el dueño del predio en el que se localiza la fuente es quien tiene prioridad para beneficiarse del recurso.

Asimismo, existen dos grupos de familias que, al carecer de fuentes de agua en sus propiedades, se abastecen de manantiales localizados en terrenos privados, de modo que con ello conforman lo que propiamente se puede considerar como sistemas de agua "privados". Cada uno de estos sistemas se compone de un tanque de captación al cual los usuarios conectan sus propias mangueras para llevar el agua a sus hogares; a cambio, deben pagar una cuota mensual al propietario del predio. Ambos sistemas se regían originalmente por relaciones de parentesco, es decir, algunas familias emparentadas entre sí compartían una fuente en común, pero con el tiempo el acceso al agua traspasó dichas relaciones para convertirse en una relación de carácter mercantil en la que interviene un "dueño" o propietario del agua, y un usuario o consumidor del líquido.

De la misma forma, otro grupo de familias que habitan en esta área se ha organizado para construir sistemas de captación al interior de la reserva; llevan el agua a un tanque de almacenamiento localizado en la propiedad de una de las familias, desde donde el líquido se distribuye para abastecer a aproximadamente diez familias. A diferencia de los sistemas "privados" arriba señalados, los usuarios no pagan ninguna cuota por acceder al recurso, si bien los costos de construcción, ampliación de las captaciones o reparación de la red, entre otros, son asumidos por los beneficiarios. Cabe señalar que en este grupo son pocas las familias que logran llevar el agua hasta sus viviendas, pues las condiciones del terreno no lo permiten, por lo que las mujeres deben acarrear el agua aproximadamente cien metros desde el tanque hasta sus viviendas, e incluso algunas deben subir una cuesta de cuarenta metros llevando consigo hasta veinte litros en un viaje. ${ }^{7}$

Un grupo de familias originarias de San Juan Chamula asentado en esta parte de la comunidad cuenta con un pequeño sistema de agua entubada cuyas captaciones se localizan al interior de la reserva natural. Este sistema abastece a entre diez y quince familias, quienes construyeron colectivamente el sistema aportando trabajo y recursos económicos, y semanalmente realizan labores de mantenimiento y limpieza mediante un sistema de rotación. Para hacer uso de una fuente de agua o construir una captación los interesados deben en primer lugar consultar a la asamblea comunitaria, ante la que exponen las necesidades y la forma en que se pretende explotar el recurso. Una vez que la asamblea otorga su visto bueno, el agente auxiliar se encarga de dar seguimiento a la acción. Cuando se trata de usar una fuente que se localiza en alguna propiedad privada, es el agente quien media en la negociación entre el propietario y los interesados.

Sin embargo, la mayor parte de las tomas de agua se localizan en el área de bosques que Los Alcanfores comparte con el resto de las comunidades del Huitepec, por lo que recurrir a fuentes localizadas en propiedades privadas es muy poco frecuente. Asimismo, los cambios en el medioambiente derivados de la pérdida de la cobertura vegetal han generado una situación de escasez de agua en general en toda la comunidad. La parte alta de ésta es la más vulnerable a tal situación dado que su abastecimiento depende principalmente de las galerías filtrantes en las que el agua aflora, las cuales se agotan con frecuencia, lo que implica que cada vez se tenga que traer el agua de lugares más lejanos. Esta situación conduce a que la población recurra a nuevos mecanismos de organización para abastecerse de este recurso que cada día se torna más escaso. 
En general, en la parte alta de la comunidad el agua es considerada como un recurso de uso común cuyo manejo se realiza como bien colectivo, a partir de grupos de entre cinco y diez familias que comparten una fuente, en un esquema de manejo que contrasta en gran medida con las prácticas de apropiación del recurso realizadas en la parte baja, las cuales se acercan cada vez más a los mecanismos institucionales de corte occidental.

De esta forma, en la sección alta de Los Alcanfores aún prevalece el esquema de apropiación del agua característico de las sociedades rurales de Los Altos de Chiapas basado en la propiedad colectiva y en el parentesco, si bien ciertos valores, creencias y rituales en torno a este bien se han transformado a lo largo del tiempo al incorporar algunos componentes de la cultura occidental. Entre los habitantes de esta área existe un conjunto de prácticas y regulaciones para el uso del agua que se respetan de forma generalizada, como ocurre en el caso de las acciones de conservación, que no se limitan a la limpieza y mantenimiento de las fuentes o captaciones. Tales prácticas incluyen tareas concretas encaminadas a la preservación del bosque, que se traducen en reglas y normas que trascienden el ámbito comunitario al involucrar también a todas las comunidades que habitan el Huitepec. En esta sección de la comunidad, las normas y regulaciones en torno a los recursos naturales se estructuran dentro de prácticas organizativas concretas, creencias y valores que, si bien no han tomado la forma de instituciones formales, tienen como rasgo fundamental el control social o el control de los grupos domésticos sobre los recursos hídricos.

\section{La parte baja: dilemas de la gestión local frente a la creciente demanda del agua}

En contraste con lo anteriormente descrito, en la parte baja de la comunidad las prácticas de apropiación del agua de sus habitantes han experimentado notables cambios derivados del crecimiento demográfico. Inicialmente, los pobladores de esta sección se abastecían de las corrientes superficiales de la comunidad como manantiales, arroyos o pozos, y de afloraciones conocidas como ojos de agua. Conforme la población fue creciendo, no sólo en esta área sino en toda la comunidad, la presión sobre los recursos se hizo más aguda, ante lo cual surgieron nuevas estrategias de abastecimiento entre las que destaca el entubado del manantial más grande de la comunidad, a partir de cuya construcción surgió el Patronato de Agua de Los Alcanfores.

Los cambios por los que ha atravesado la comunidad han incidido en la gestión del agua en la sección baja de Los Alcanfores. Esta situación se hace patente en la organización del Patronato y en la diversificación de sus funciones pues, de ser inicialmente una instancia encargada de mantener en buen estado las captaciones y la red de distribución, pasó a desarrollar actividades como cobrar las cuotas a los usuarios, aprobar las nuevas solicitudes de conexión y gestionarlas, mantener y vigilar el buen estado de los tanques de almacenamiento y las tuberías, y realizar trámites relacionados con el agua ante instancias gubernamentales. A ello también se añade la tarea de negociar, tanto al interior de la comunidad - con el grupo de habitantes de la parte alta- como fuera de ésta, el acceso a las fuentes de agua, lo que incluye actividades de conservación de los bosques, que constituyen la base del área de captación del manantial que abastece a la comunidad. ${ }^{8}$

En el ámbito externo, la comunidad mantiene acuerdos en torno al uso del área boscosa, sobre la cual existe un decreto oficial de área natural protegida, ${ }^{9}$ uso que se comparte con el resto de las comunidades de las faldas del volcán. El eje de tales acuerdos es regular el acceso a los manantiales ubicados en la reserva de 102 hectáreas de bosque (García, 2005). De esta manera, la gestión del agua en Los Alcanfores posee dos dimensiones: la que se refiere a la apropiación, uso y acceso del recurso, y aquella vinculada con la conservación del bosque. Dado que el agua proviene de un área preservada por todos los habitantes del Huitepec, las formas de apropiación que la población de la parte baja realiza del agua generan conflictos a nivel externo, ya sea por la centralización del recurso, por la manera de operar del Patronato o por las constantes pugnas por la apropiación de la reserva natural. 
Cabe mencionar también que, por la presión sobre los recursos hídricos y los conflictos que se han generado en torno a su gestión en la parte más baja de la comunidad, un grupo de usuarios del Patronato, entre los que se encuentran algunos fraccionadores privados y otros avecindados que no contaban con el servicio de agua entubada, ha logrado obtener el servicio por parte del Sistema de Agua Potabley Alcantarillado Municipal (SAPAM).

Con ello se observa que la creciente presión sobre el agua en la parte baja de Los Alcanfores ha derivado en la diversificación de las estrategias para regular su uso y el acceso a ella, entre las que encontramos desde la reglamentación sobre el uso del agua a fin de evitar que se desperdicie, la vigilancia de la reserva y las labores de reforestación en la misma, hasta la determinación tomada por el Patronato de no aceptar nuevas solicitudes de conexión al sistema. El incumplimiento de las normas establecidas es sancionado por la asamblea con el corte del servicio de agua. Un hecho que salta a la vista es que, por lo general, las sanciones suelen ser más enérgicas cuando el infractor es un avecindado, ya que los pobladores originarios afirman que este sector es el que cuenta con mayores recursos económicos, pero sobre todo porque consideran que son ellos los que consumen la mayor cantidad de agua ya que la suelen utilizar de manera más constante y cuentan con mejores condiciones para almacenarla a través de cisternas y tinacos.

Frente a esta situación existe en la comunidad un escenario de acceso diferencial al recurso en el que intervienen variables físicas y ambientales, ya que la topografía comunitaria determina que la disponibilidad de las fuentes sea mayor en las partes media y baja de la comunidad, que es donde se localizan primordialmente los afloramientos hídricos. Esta situación se combina con la estructura socioespacial de la comunidad, lo que genera tensiones y conflictos entre los habitantes de las partes baja y alta de la comunidad, que a la larga se convierten también en conflictos entre actores sociales urbanos y un grupo de actores rurales representado por los habitantes originarios que residen en la parte alta de la comunidad y por las comunidades vecinas.

\section{El acceso al agua en la periferia urbana, entre la gestión local y la gestión municipal}

Frente a un escenario de disputas crecientes en torno al agua, los habitantes de Los Alcanfores han desarrollado nuevos mecanismos para regular el acceso al recurso. Tales estrategias, sin embargo, no han mostrado ser suficientes en la medida en que las disputas persisten y se agudizan paulatinamente. Asimismo, es notable observar que la forma de acceso a los recursos naturales adoptada por los habitantes de la parte baja se aleja cada vez más del esquema tradicional que aún prevalece entre los pobladores de la parte alta y, en general, en el resto de las comunidades del Huitepec.

Una dimensión de esta problemática son los conflictos por el agua, entendidos como acceso diferencial entre los pobladores de las distintas secciones de la comunidad, y entre la población originaria y los avecindados. Sin embargo, de fondo existe un plano mucho más amplio, una lucha por el control de los recursos naturales, en particular de la tierra, ya que ésta posee un valor económico - por tratarse de terrenos para uso habitacional- entre los distintos grupos de actores que existen en el Huitepec.

Las tensiones en torno al agua en la comunidad han provocado que los pobladores de la parte baja, particularmente el grupo de los avecindados, pugne para que la gestión del Patronato se apegue a la normatividad oficial vigente en materia de agua, lo cual se convierte en un ingrediente más en la disputa.

En ese sentido, las formas de organización y de acceso a los recursos naturales de la población de Los Alcanfores, y en general de las comunidades del Huitepec, están basadas en las costumbres ancestrales que les fueron legadas históricamente en la medida en que los abuelos de los actuales pobladores del área eran de origen indígena. Si bien la gestión del Patronato considera el recurso como un bien común - en el entendido de que las cuotas pagadas por los usuarios sólo son de recuperación-, la operación de dicha instancia está transformando paulatinamente las costumbres y creencias tradicionales. Lo hace, por un lado, al incorporar prácticas de conservación del recurso 
como la reforestación del bosque, o bien al reglamentar el uso del agua, lo que tiene como fin principal evitar que ésta se desperdicie, ya que tales consideraciones de carácter ambiental se basan en la relación entre los elementos suelo, bosque y agua, retomada de la cultura occidental. Otras acciones de conservación de los recursos implementadas por la comunidad en su conjunto han consistido en impedir la tala de árboles grandes - maderables - y en no permitir el corte de leña verde para hacer carbón; el cumplimiento de estas acciones es apoyado por un grupo de mujeres que vigilan la reserva.

Por otro lado, cuando el Patronato incorpora valores ambientales de corte occidental en la gestión del recurso, en cierta medida se aleja de la concepción tradicional, según la cual tierra, agua, flora y fauna son propiedad de un ser que habita dentro del volcán del Huitepec al cual se venera y respeta. En relación con este último aspecto, prevalecen aún las ceremonias en torno al agua realizadas por los habitantes del Huitepec que también celebran los habitantes de Los Alcanfores, incluyendo los de la sección baja, las cuales incluyen una mezcla de elementos de origen católico e indígena. Sin embargo, en la zona que nos ocupa estas celebraciones presentan ciertas diferencias con respecto a la forma en que se llevan a cabo en las otras comunidades de la zona ya que los rezos no se hacen en tsotsil, sino en español, y están a cargo de una mujer que también cuida el templo.

De esta manera, el cuidado del volcán o de la naturaleza, y en particular del agua, se materializa a partir de una mezcla de concepciones sociales de orígenes indígena y occidental. Pero la existencia de esta dualidad cultural entre lo mestizo y lo indígena se convierte en un elemento determinante en caso de disputas por los recursos naturales, máxime cuando se cuenta con la presencia de avecindados mestizos dentro de la comunidad, entre quienes destacan algunos miembros de la élite política tanto local, como estatal. En general, la mayor parte de estos avecindados mestizos mantiene un nivel de vida superior al que poseen los habitantes originarios. Tal situación se pudo observar cuando entre 2003 y 2004, a raíz de la construcción de la ermita católica por parte de los habitantes de Los Alcanfores en terrenos de la reserva, se rompieron los acuerdos relacionados con respetar el bosque que habían sido signados entre las comunidades del Huitepec. Ello provocó que la comunidad de Los Alcanfores se dividiera entre quienes estaban a favor de la conservación del área de bosques, y quienes, aliados con grupos de otras comunidades, demandaban la repartición de las 102 hectáreas. Frente a esta situación, el grupo de avecindados de la zona baja presionó al Patronato para buscar el cobijo de las leyes del Estado y de esa manera asegurarse el acceso al agua.

En ese contexto, el Patronato logró que en agosto de 2003 la junta de cabildo local lo reconociera como sistema de agua independiente, con personalidad jurídica y patrimonio propio, lo cual desde el punto de vista de los avecindados constituyó un paso muy importante. Frente a ello, era de esperarse que el segundo paso fuera que los avecindados obtuvieran una concesión de la Comisión Nacional del Agua (CONAGUA). Para los usuarios del Patronato, una concesión de esta naturaleza significaría el reconocimiento oficial de sus derechos sobre las fuentes explotadas, además de que el título de concesión de derechos de agua le otorgaría al Patronato el dominio sobre los recursos hídricos que actualmente explota. Sin embargo, esta posición se confronta con la que mantienen los habitantes de la sección alta, quienes bajo ninguna circunstancia están dispuestos a aceptar la intervención de la CONAGUA para regularizar el acceso a las fuentes de agua que les abastecen, en la medida en que consideran que el volcán o la montaña, como le nombran, está vivo, y su forma de manifestarse es a través del agua que surge de los manantiales, la cual es aprovechada por las comunidades (García, 2005: 182).

En estas circunstancias es preciso señalar que, si bien en la comunidad prevalecen las prácticas que tienen como eje la concepción del agua como un bien común, la heterogeneidad social de Los Alcanfores ha derivado en un punto de discordia en torno al agua. Por esta razón, el hecho de que el Patronato busque la protección de la normatividad vigente en materia de agua coloca al resto de la comunidad, sobre todo a los habitantes de la zona alta, en una situación vulnerable 
dado que sus prácticas tradicionales de manejo de agua no son reconocidas por las leyes del Estado mexicano.

Es preciso recalcar, sin embargo, que la ausencia de la participación del Estado para garantizar el abastecimiento de agua ${ }^{10}$ aumenta los mecanismos de cooperación y generación de propuestas alternas para el abasto de este recurso, y con ello los mecanismos comunitarios y de resistencia, lo que implica la generación de situaciones de cooperación y de solidaridad. En el caso de Los Alcanfores, más allá de la cooperación y la acción interna para la preservación de un recurso tan importante, al exterior surgen situaciones de tensión por la inconformidad de los actores con quienes se comparte la reserva forestal debido a las formas de apropiación y acceso a las tierras, que en este caso son las de mayor interés.

La gestión del agua en la zona sigue estando fundada sobre la base de acuerdos comunitarios, pero también sobre el marco institucional ya que, a raíz de un conflicto suscitado en el año 2003, han surgido presiones para que la operación del Patronato de Agua de Los Alcanfores se apegue a la normatividad oficial, aunque ello no se haya hecho realmente efectivo. Sin embargo, consideramos que el manejo común continúa siendo vulnerable a las presiones derivadas del crecimiento de la mancha urbana y a la presión sobre la tierra, lo que, en un caso extremo, puede conducir a que los habitantes de la comunidad abandonen la gestión comunitaria para demandar la intervención de las autoridades gubernamentales en la operación del sistema de agua de la parte baja.

Otro factor que está generando un cambio de estrategia en la gestión del recurso a nivel comunitario, y que podría conducir a que los habitantes de Los Alcanfores y las comunidades vecinas del área de 102 hectáreas de bosques pierdan el control de éste, fue la creación de la reserva comunitaria en 2007 bajo el amparo de la Junta del Buen Gobierno de Oventic ${ }^{\text {ll }}$ del Ejército Zapatista de Liberación Nacional (EZLN). La creación de esta reserva comunitaria ha significado la exclusión de los pobladores de la parte alta de Los Alcanfores del uso y acceso a las áreas de bosque, así como la prohibición de la extracción de agua, leña y tierras de cultivo de la reserva. Esta situación ha conducido a que un grupo de pobladores de la parte alta trascendiera el ámbito interno para solicitar el amparo de las instancias oficiales a fin de obtener su apoyo para satisfacer la demanda del líquido, y al mismo tiempo han acudido a la Junta del Buen Gobierno del EZLN para solicitar que se les autorice la ampliación de sus captaciones al interior de la reserva.

Nuevamente, con acciones como éstas se observa que, frente a una situación de conflicto, los actores locales recurren a la intervención de las instituciones del Estado nacional para mediar y regular sobre el acceso al recurso. De esta forma, mientras el esquema oficial establece que tanto el agua, como en este caso también los bosques, son bienes nacionales, en el ámbito local prevalecen prácticas que tienen como eje la concepción del agua y los bosques como bienes comunes por parte de las sociedades locales. No obstante, cuando se ve limitada la capacidad de éstas para decidir sobre el uso y la distribución de los recursos mencionados, se recurre a las instancias gubernamentales. Ante ello, el desencuentro entre las prácticas locales y la gestión que el Estado hace del recurso sigue generando conflicto en ciudades como San Cristóbal de Las Casas, donde han sido muy marcadas las limitaciones de la gestión municipal, particularmente en el caso de los recursos hídricos. Por esta razón, las instancias de la administración pública continúan ausentes en el área.

\section{Conclusiones}

El manejo local de los recursos hídricos en el caso aquí presentado, basado en arreglos y normas diseñadas para controlar y preservar el agua y el territorio por parte de los pobladores locales, constituye uno de los tantos ejemplos de gestión local del agua que se repiten a lo largo del territorio nacional, y que se fortalecieron a lo largo del siglo XX como medida de resistencia ante el modelo de manejo centralizado de las aguas nacionales promovido por el Estado mexicano durante el mismo periodo (Aboites, 2009: 15). Este modelo de gestión del recurso en México encontró resistencias y dificultades para su implementación debido a la heterogeneidad sociocultural 
en las distintas regiones del país, prevaleciendo así las formas tradicionales de uso del agua. Desde 1992, las reformas constitucionales a la Ley de Aguas Nacionales introdujeron un cambio de paradigma; en este nuevo modelo el mercado aparece como la promesa para resolver la distribución y asignación del recurso hídrico, mientras el Estado asume el papel de regulador en el nuevo mercado de aguas (Aboites, 2009: 93). En este marco, es pertinente preguntarnos acerca de los nuevos retos del manejo del agua en el ámbito local, en este caso, en los espacios periurbanos de Los Altos de Chiapas, donde las formas tradicionales de gestión del líquido se confrontan con las visiones y modos de apropiación de los actores urbanos, lo que conduce a la generación de arreglos sociales novedosos.

\section{Notas}

${ }^{1}$ El territorio que actualmente ocupa la ciudad de San Cristóbal de Las Casas es conocido comúnmente como Valle de Jovel; sin embargo este territorio no es propiamente un valle, sino un poljé es decir, una depresión de origen cárstico de fondo plano y de tamaño considerable. Por lo general, en este tipo de formaciones es común que circule algún río o corriente cárstica, que se caracteriza por ser superficial en parte de su trayectoria y desaparecer en sumideros naturales ya que el poljé es un territorio cerrado.

2 Huitepec Los Alcanfores, Vistahermosa, Huitepec Ocotal secciones I y II, Santa Anita, Las Palmas y Las Flores.

${ }^{3}$ Los terrenos nacionales son definidos por la Ley Agraria como aquellos terrenos baldíos que fueron deslindados y medidos, o bien aquellos que ha recobrado la nación por haberse decretado la nulidad de los títulos por los cuales fueron otorgados a ejidos, comunidades o particulares.

${ }^{4}$ En referencia al término "coleto", si bien originalmente designaba a la élite local descendiente de los colonizadores españoles, hoy en día engloba a los mestizos originarios de San Cristóbal de Las Casas.

${ }^{5}$ De acuerdo con la Carta Urbana del Plan de Desarrollo Urbano Municipal de 2006-2020, el área urbana de Los
Alcanfores abarca el territorio que va desde la carretera a San Juan Chamula, hasta el periférico y el camino a San Felipe. Tiene una extensión de 1032.01 hectáreas. En ésta se ubican alrededor de veinticinco colonias, además de las comunidades Los Alcanfores y Vista Hermosa, todas ellas de creación reciente. Muchas de éstas se encuentran en proceso de regularización; se trata de desarrollos habitacionales de tipo campestre realizadas en propiedades privadas donde, sin embargo, el acceso al agua entubado aún es limitado (Secretaría de Obras Públicas, 2007).

${ }^{6}$ El patronato es en realidad una figura jurídica impuesta por la CONAGUA para todo sistema independiente de los esquemas municipales.

${ }^{7}$ En fechas recientes se ha observado la llegada de nuevos habitantes a la comunidad. Muchas de las nuevas familias se han asentado en el área aledaña a la escuela, ocupando terrenos alrededor de la reserva comunitaria. Esta situación ha llevado a la búsqueda de nuevas alternativas para el abastecimiento de agua. Actualmente se han construido nuevos tanques de almacenamiento para aprovechar el cauce del manantial principal de Los Alcanfores que distribuyen el agua a las viviendas de los alrededores a través de mangueras. Se ha observado, asimismo, que numerosas mujeres acuden a este sitio para lavar ropa y acarrear agua a sus viviendas.

${ }^{8}$ Las actividades de conservación que realiza el Patronato consisten básicamente en la reforestación en partes en que se ha perdido la cobertura vegetal al interior de la reserva, y la limpieza de las calles y el bosque. La reforestación se realiza anualmente y en esta actividad participan todos los miembros de la comunidad, pero particularmente los usuarios del sistema de agua.

${ }^{9}$ A propósito de las crecientes disputas por la tierra y los recursos naturales en el Huitepec, distintos grupos demandaron a las instancias oficiales para demandar el resguardo de la reserva de bosques como medida para contener el avance de la mancha urbana sobre dichas tierras, pero también para frenar el constante saqueo de los recursos naturales del área. Esta medida fue impulsada principalmente por un grupo de avecindados de Los Alcanfores. Como resultado, en marzo de 2007 el 
gobierno del estado publicó un decreto mediante el cual se establecen las 102 hectáreas en disputa como zona sujeta a conservación, bajo la administración conjunta del Instituto de Historia Natural y de Ecología del Estado de Chiapas y PRONATURA A.C.

${ }^{10}$ En San Cristóbal de Las Casas han sido muy marcadas las limitaciones de la gestión municipal de los recursos hídricos. Ello ha permitido la existencia de sistemas independientes de suministro de agua: La Garita, Cuxtitali y Los Alcanfores. De esta forma, la gestión del recurso en la cuenca es determinada por las acciones de tres tipos de actores en distintos niveles: federal a través de la CONAGUA, municipal por intermediación del Sistema de Agua Potable y Alcantarillado (SAPAM), y local desde las distintas organizaciones de usuarios, o bien, en este caso, a través de los patronatos de agua potable (García, 2005: 128).

${ }^{11}$ Las Juntas de Buen Gobierno están constituidas por representantes de los municipios autónomos zapatistas que se agrupan en regiones organizativas conocidas como Caracoles. Su papel consiste en fortalecer la unión y la coordinación entre los municipios autónomos y las regiones tanto a nivel organizativo, como en lo que se refiere a proyectos comunitarios; otra función que cumplen es la de enlace entre las comunidades zapatistas y la sociedad civil en general.

\section{Referencias bibliográficas}

Aboites, Luis (2009). La decadencia del agua de la nación. Estudio sobre desigualdad social y cambio político en México. Segunda mitad del siglo XX. México: El Colegio de México.

Appendini, Kirsten y Monique Nuijten (2002). “El papel de las instituciones en contextos locales". En Revista de la CEPAL, 76, abril, pp. 71-87.

Aubry, Andrés (1991). San Cristóbal de Las Casas. Su historia, demográfica y monumental 1528-1990. San Cristóbal de Las Casas, Chiapas: INAREMAC.

Boelens, Rutgerd y Paul Hoogendam (2001). Derechos de agua y acción colectiva. Lima: Instituto de Estudios Peruanos.
Burguete, Aracely (2000). Agua que nace y muere. Sistemas normativos indígenas y disputas por el agua en Chamula y Zinacantán. México: PROIMMSE-UNAM.

CONAGUA (2011). Situación del Subsector agua potable, alcantarillado y saneamiento. México: CONAGUA.

CONAGUA (2014). Estadísticas del agua en México. México: CONAGUA.

García, Antonino (2005). "La gestión del agua en la Cuenca Endorreica de San Cristóbal de las Casas, Chiapas, México". Tesis de maestría, Universidad Autónoma de Chapingo, San Cristóbal de Las Casas, Chiapas.

Kauffer, Edith (2009). "Donde el agua de la nación tiene dueños: la relación entre agua y tierra en los Altos de Chiapas". En Jesús Gómez Serrano Aquiles Omar Ávila Quijas, Antonio Escobar Ohmstede, Martín Sánchez Rodríguez (coords.), Negociaciones, acuerdos y conflictos en México, siglos XIX y XX: Aguay tierra. México: CIESAS. COLMICH, Universidad Autónoma de Aguascalientes, pp. 401-437.

Moguel, Reyna (1997). "Sistemas sociales en Los Altos de Chiapas". Tesis de doctorado, Universidad Nacional Autónoma de México, México.

Murillo, Daniel (2005). Encima del mar está el cerro y ahí está el Ángel. Significación del agua en una comunidad tzotzil. México: IMTA.

Secretaría de Obras Públicas (2007). Programa de Desarrollo Urbano de San Cristóbal de las Casas, Chiapas; 2006-2020. México: la Secretaría.

Viqueira, Juan Pedro (2007). "Historia crítica de los barrios de Ciudad Real”. En Dolores Camacho, Arturo Lomelí y Paulino Hernández (coords.), La ciudad de San Cristóbal de Las Casas: a sus 476 años. Una mirada desde las ciencias sociales. Colección Hechos en Palabras. San Cristóbal de Las Casas, Chiapas: Gobierno del Estado de Chiapas, pp. 29-59.

Zárate, María Antonieta (2008). "Gestión del agua y conflicto en la periferia urbana de San Cristóbal de Las Casas, Chiapas. El caso de Los Alcanfores". Tesis de maestría. San Cristóbal de Las Casas, Centro de Investigaciones y Estudios Superiores en Antropología Social, Unidad Sureste, Chiapas, México. 


\section{Mapa 1. Ubicación geográfica del área de estudio}

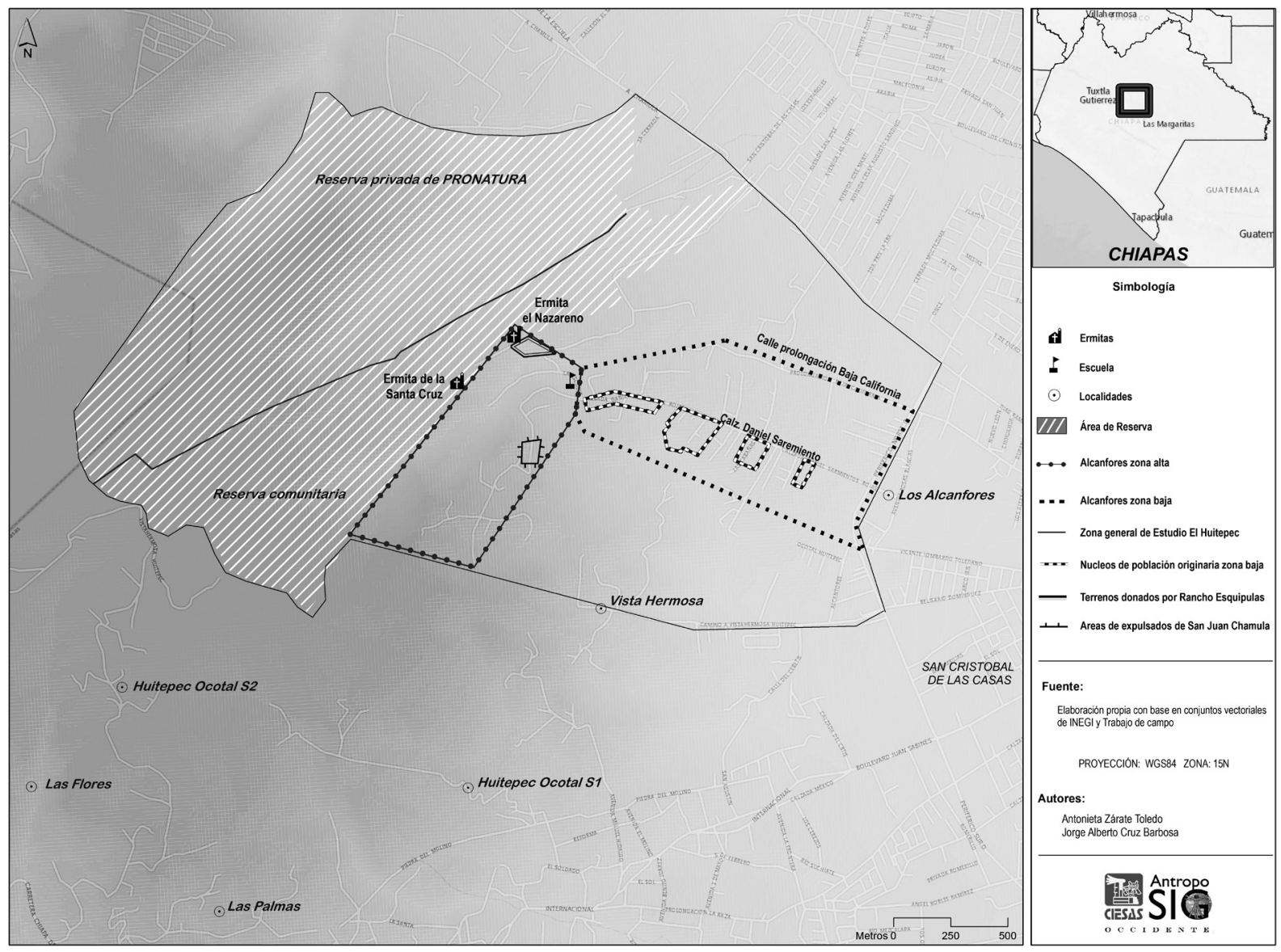

Fuente: Elaboración propia con base en conjuntos vectoriales del INEGI y trabajo de campo. 